\title{
Synthesis and biocompatibility study of ceria-mildronate nanocomposite in vitro
}

A. L. Popov ${ }^{1, a}$, D. D. Kolmanovich ${ }^{1, b}$, N. R. Popova ${ }^{1, c}$, S. S. Sorokina ${ }^{1, d}$, O. S. Ivanova ${ }^{2, e}$, N. N. Chukavin ${ }^{1,3, f}$, A. B. Shcherbakov ${ }^{4, g}$, T. O. Kozlova ${ }^{2, h}$, S. A. Kalashnikova ${ }^{5, j}$, V. K. Ivanov ${ }^{2, k}$

${ }^{1}$ Institute of Theoretical and Experimental Biophysics of the Russian Academy of Sciences, 142290, Russia

${ }^{2}$ Kurnakov Institute of General and Inorganic Chemistry of the Russian Academy of Sciences, 119991, Russia

${ }^{3}$ Moscow Region State University, 141014, Moscow, Russia

${ }^{4}$ Zabolotny Institute of Microbiology and Virology, Kyiv D0368, Ukraine

${ }^{5}$ 40th City clinical hospital, Ekaterinburg, 620102, Russia

${ }^{a}$ antonpopovleonid@gmail.com, ${ }^{b}$ kdd100996@mail.ru, ${ }^{c}$ nellipopovaran@gmail.com,

${ }^{d}$ sorokinasvetlana.iteb@gmail.com, ${ }^{e}$ runetta05@mail.ru, ${ }^{f}$ chukavinnik@gmail.com,

${ }^{g}$ ceroform@gmail.com, ${ }^{h}$ tasiok@mail.ru, ${ }^{j}$ kalashnikova.sana@mail.ru, ${ }^{k}$ van@igic.ras.ru

Corresponding author: A. L. Popov, antonpopovleonid@gmail.com

PACS 68.65.-k, 81.20.-n, 82.70. Dd, 87.80.-y

ABSTRACT Nanoscale cerium dioxide $\left(\mathrm{CeO}_{2}\right.$, nanoceria) possesses notable redox activity, which is actively used in advanced biomedical applications. The low toxicity, high biocompatibility and antioxidant activity of nanoceria make it a new generation nanozyme with a unique activity. Combination of nanoceria with various biologically active substances results in organic-inorganic nanocomposites possessing enhanced activity. Here, we synthesized a novel organic-inorganic hybrid material $\left(\mathrm{Mil}^{-} \mathrm{CeO}_{2}\right)$ based on 2-(2-carboxylatoethyl)1,1,1-trimethylhydrazinium and nanoceria, which has an ultra-small particle size, high antioxidant activity and pronounced biological activity. The analysis of cytotoxicity of the composite did not reveal any negative effects on the NCTC L929 mouse fibroblasts at concentrations below $10 \mathrm{mM}$. It was shown that the nanocomposite did not cause morphological changes in cells, or lead to cell death and mitochondrial membrane potential

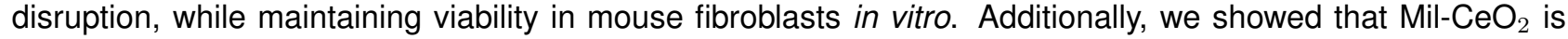
capable of protecting cells from hydrogen peroxide $\left(\mathrm{H}_{2} \mathrm{O}_{2}\right)$-induced or radiation-induced oxidative stress.

KEYWORDS cerium oxide nanoparticles, nanoceria, 2- (2-carboxylatoethyl) -1,1,1-trimethylhydrazinium, toxicity, nanocomposite

ACKNOWLEDGEMENTS The work was supported by the Russian Science Foundation (project 20-74-00086). The research was carried out using the equipment of MSU Shared Research Equipment Center "Technologies for obtaining new nanostructured materials and their complex study" and purchased by MSU in the frame of the Equipment Renovation Program (National Project "Science") and in the frame of the MSU Program of Development.

FOR CITATION Popov A.L., Kolmanovich D.D., Popova N.R., Sorokina S.S., Ivanova O.S., Chukavin N.N., Shcherbakov A.B., Kozlova T.O., Kalashnikova S.A., Ivanov V.K. Synthesis and biocompatibility study of ceriamildronate nanocomposite in vitro. Nanosystems: Phys. Chem. Math., 2022, 13 (1), 96-103.

\section{Introduction}

Cerium oxide nanoparticles (CNPs) are considered as the most versatile inorganic antioxidant [1-3]. CNPs redox activity is probably due to a high degree of oxygen nonstoichiometry, which is due to the presence of defects in the crystal lattice of $\mathrm{CeO}_{2}$ nanoparticles [4-7]. Cerium oxide nanoparticles are capable of inactivating a wide range of reactive oxygen species (ROS) and free radicals [8-11], preventing the development of intracellular oxidative stress in vitro $[12,13]$ and in vivo [14-16]. It is also well known that cerium oxide nanoparticles mimic the activity of endogenous enzymes such as superoxide dismutase (SOD) [17-19] and catalase [20]. Cerium oxide nanoparticles are considered as a promising anticancer [21-23], antibacterial [24-26] and antiviral [27-29] agent as well as a promising inorganic antioxidant for diverse biomedical applications [30-32].

We have previously shown that cerium dioxide nanoparticles demonstrate a synergistic effect with well-known anticancer drugs or another therapeutic substances, enhancing their effect [33-36]. In particular, it has been shown that the panthenol-cerium dioxide complex protects testicular epithelial cells (ST cells) from oxidative stress caused by hydrogen peroxide or UV radiation [37]. Similarly, conjugation with cerium dioxide affects the cytotoxicity and photocytotoxicity of curcumin, depending on the cell type, being more toxic for cancer cells. The nanoceria-curcumin conjugate demonstrated highly selective cytotoxicity under oxidative stress conditions induced by UVA/UVC irradiation or $\mathrm{H}_{2} \mathrm{O}_{2}$, causing a 
dramatic inhibition of metabolic activity of cancer cells and protecting normal cells from these damaging factors [38]. The combination of recombinant TNF-alpha with cerium dioxide nanoparticles has been shown to provide a stronger and more stable cytotoxic effect in Hep-2 and A-549 tumor cell lines [39]. Thus, the design and study of hybrid ceriumcontaining nanocomposites could be a promising tool for creating advanced functional materials with a therapeutic activity exceeding that of the individual components (synergism).

There are a large number of promising drugs that could act as a synergistic agent for cerium dioxide nanoparticles. One possible candidate is meldonium, which is a small, highly hydrophilic molecule that has no affinity for plasma proteins. Upon administration, the maximum plasma concentration of meldonium is reached after about 1 hour, and its half-life depends on the dosage, treatment time and pharmaceutical form. Meldonium is metabolized mainly in the liver by gamma-butyrobetaine hydroxylase (BBOX) to form dimethylamine, 2-hydroxymethyl-2-(hydroxymethylamino) propane-1,3-diol, 3-amino-4-(hydroxymethylmethylamino). The latter metabolite can be converted to succinic acid, the main metabolite found in plasma. Mildronate is regarded as a mitochondria-targeted drug as it easily penetrates into mitochondria and enters the metabolic cycle [40,41]. Mitochondrial damage can activate free radical processes and lead to the initiation of apoptosis, as well as disruption of mitochondrial oxidative phosphorylation, damage to the endoplasmic reticulum and changes in gene activity [42-44]. Mitochondria are the main site of ROS formation in the cell. There are several factors that determine ROS generation in mitochondria: the presence of different metabolic intermediates, hypo/hyperoxia, an increase in the concentration of NADH or membrane mitochondrial potential (MMP). Thus, the development and study of a new mitochondria-targeted biologically active nanocomposites is an urgent task. To summarize, the ceria-mildronate composite can be considered as a promising substance for inhibiting the oxidative stress and increasing the cell metabolic status.

\section{Materials and methods}

\subsection{Synthesis and characterization of nanocomposite}

The ceria-mildronate composite $\left(\mathrm{CeO}_{2}\right.$-Mil) was synthesized in two stages. Initially, cerium (III) trimeldonate solution was obtained by mixing $500 \mathrm{mg}$ sodium mildronate $(3.48 \mathrm{mM})$ with cerium chloride $\left(\mathrm{CeCl}_{3} \cdot 7 \mathrm{H}_{2} \mathrm{O}\right)$ in a molar ratio of 3:1 with thorough stirring. Next, we synthesized nanoscale cerium dioxide composite with meldonium $\left(\mathrm{CeO}-\mathrm{Mil}_{2}\right.$ by precipitation using $\mathrm{NaOH}(1 \mathrm{M})$. The composite was separated by decantation and then centrifuged at 10,000 rpm and washed three times with MQ water. $\mathrm{CeO}_{2}$-Mil composite sol was sonicated for 1 hour before using. The hydrodynamic diameter and the $\zeta$ - potential values were measured using a Zetasizer Nano ZS analyzer (Malvern Instruments Ltd., UK). High-resolution transmission electron microscopy (HR-TEM) analysis was performed using a Libra 200 MC microscope (Zeiss, Germany). TEM images were recorded by a CCD camera (Gatan, USA) with a matrix size of $4096 \times 4096$ pixels.

\subsection{Cell culture}

The analysis of cytotoxicity and bioactivity was carried out using NCTC clone L929 cell culture from the Institute of Cell Biophysics collection; NCTC clone L929 fibroblasts were obtained from the subcutaneous connective tissue of $\mathrm{C} 3 \mathrm{H} / \mathrm{An}$ mice. The cells were seeded in 96-well plates at a density of $2 * 10^{4}$ per $\mathrm{cm}^{2}$ in DMEM/F12 medium (1:1) supplemented with $10 \%$ fetal bovine serum (FBS) and $100 \mathrm{U} / \mathrm{ml}$ penicillin/streptomycin solution. Cells were cultivated under $5 \% \mathrm{CO}_{2}$ at $37^{\circ} \mathrm{C}$.

\subsection{MTT assay}

Cell viability was assessed using the MTT test. The cells were seeded in 96-well plates and cultivated for 24 hours. $6 \mathrm{~h}$ after cell seeding, the culture medium was replaced with a medium containing $\mathrm{CeO}_{2}$-Mil nanocomposite at various concentrations $(0.05-11 \mathrm{mM})$. Cells with the medium, but without $\mathrm{CeO}_{2}$-Mil nanocomposite, were used as a control. $24 \mathrm{~h}$ after the introduction of the nanocomposite, the medium in wells was replaced with a medium containing 3-4,5dimethylthiazol-2-yl-2,5-diphenyltetrazole $(5 \mathrm{mg} / \mathrm{ml})$. The optical density of the formed formazan was determined at a wavelength of $\lambda=540 \mathrm{~nm}$ using a BIO-RAD model 680 photometer.

\subsection{Live/Dead assay}

To assess the ratio of living/dead cells in culture, we used the L-7007 LIVE/DEAD BacLight Bacterial Viability Kit (Invitrogen) containing SYTO 9 (stains all cells, $\lambda=485 / 498 \mathrm{~nm}$ ) and propidium iodide (stains the nuclei of dead cells, $\lambda=535 / 617 \mathrm{~nm}$ ) dyes. Cell staining was performed by replacing the culture medium with a dye mixture $(5 \mu \mathrm{M})$. Observation of morphology and fluorescent staining was carried out on an Axiovert 200 inverted microscope (Carl Zeiss). Microphotography was performed using a Power Shot A620 digital camera (Canon). Stained cells were counted using the Image J software. 


\subsection{Mitochondrial membrane potential (MMP level) analysis}

The MMP level was assessed using tetramethyl rhodamine, TMRE (Thermo Fisher Scientific, USA). TMRE is a positively charged red-orange dye that penetrates cells and accumulates readily in active mitochondria due to their negative membrane potential. Depolarized or inactive mitochondria have a reduced membrane potential and are unable to accumulate TMRE. The TMRE excitation peak is $488 \mathrm{~nm}$, the emission peak is $575 \mathrm{~nm}$. The preparation of the working solution with the dye was carried out in Hanks solution, upon the addition of the prepared solution to the cells, cultivation was carried out for 15 minutes. Before the study itself, using microscopic methods, the solution with the dye was replaced with the Hanks solution. The work was carried out under sterile conditions in a laminar flow hood. For the study, we used an Axiovert 200 Zeiss inverted fluorescence microscope. Then, the level of fluorescence intensity was calculated using ImageJ.

\subsection{Fluorescent staining of cell nuclear with Hoechst 33342 dye}

Cells were cultured in 96-well plates, as described above. After 24 hours of culturing with nanocomposite, the cells were washed with HBSS, prior to 20 min staining with Hoechst $33342(5 \mu \mathrm{M})$. Images of stained cells were captured by a fluorescence microscope Zeiss Axiovert 200.

\subsection{Oxidative stress model in vitro}

The protective action of $\mathrm{CeO}_{2}$-Mil nanocomposite was analyzed using two experimental models of oxidative stress: single dose X-ray irradiation ( $15 \mathrm{~Gy}$ ) or hydrogen peroxide treatment ( $1 \mathrm{mM}$ for 30 minutes). Cell viability analysis was performed using MTT test after 24 hours for hydrogen peroxide treatment and after 72 hours for X-ray irradiation, respectively.

\subsection{Statistical analysis}

Data are presented as standard deviation from the mean value. The significance of differences between experimental groups was assessed by the Mann-Whitney U-test.

\section{Results and discussion}

The synthesis of $\mathrm{CeO}_{2}$-Mil nanocomposite was carried out according to the scheme shown in Fig. 1a. The hydrodynamic radius of the nanocomposite upon dilution in water was approximately 15-20 nm (Fig. 1b). The zeta potential of the particles when diluted in distilled water was $+23 \pm 3.2 \mathrm{mV}$. According to TEM data, the particle size of the nanocomposite was 4-5 nm (Fig. 1c). The synthesized $\mathrm{CeO}_{2}-\mathrm{Mil}$ nanocomposite demonstrated good colloidal stability and can be stored for at least 7 days without any signs of sedimentation.

It is well known that cerium oxide nanoparticles coated by biocompatible ligands are not toxic to mammalian cells in vitro and in vivo, even at high concentrations [45-47]. For example, citrate-stabilized cerium oxide nanoparticles do not cause toxic effects in the culture of mouse embryonic fibroblasts, while maintaining a high level of their migratory, proliferative and metabolic activity [48]. In turn, dextran-stabilized gadolinium-doped cerium oxide nanoparticles have demonstrated selective toxicity against cancer cells [49]. Nevertheless, each new synthesis scheme for $\mathrm{CeO}_{2}$ nanoparticles preparation and stabilization requires a comprehensive analysis of cytotoxicity to analyze the prospects for biomedical use.

The cytotoxicity of the $\mathrm{CeO}_{2}$-Mil nanocomposite was analyzed using mouse fibroblasts cell line NCTC L929 (Fig. 2). The $\mathrm{CeO}_{2}$-Mil nanocomposite was shown to have no toxic effect and provided a high level of metabolic activity at the concentrations below $1 \mathrm{mM}$. It should be noted that cerium (III) chloride in high concentrations (above $1 \mathrm{mM}$ ) was toxic for mouse fibroblasts, while this was not the case for $\mathrm{CeO}_{2}-\mathrm{Mil}$ nanocomposite. Additionally, an assessment of the toxicity of mildronate and cerium chloride at the same concentrations was carried out. Analysis of the ratio of live and dead cells using the differential staining method has shown that the $\mathrm{CeO}_{2}$-Mil nanocomposite does not cause cell death at all studied concentrations $(0.05-11 \mathrm{mM})$, retaining the native morphology and phenotypic features characteristic of fibroblasts (Fig. 3b).

Mitochondria are redox-sensitive organelles [50]. The mitochondrial disruption is accompanied by the changes in the membrane potential and alterations to the oxidation-reduction potential of the mitochondria. Previously, it was shown that nanoceria could depolarize mitochondrial membrane of human colon cancer cells [51]. In the current study, it was revealed that preliminary incubation of NCTC $\mathrm{L} 929$ with $\mathrm{CeO}_{2}-\mathrm{Mil}$ nanocomposite did not lead to any changes in the MMP in any of the concentrations thus confirming the high biocompatibility of the nanocomposite (Fig. 3c)

The results of Ce-Mil nanocomposite protective effects study are presented in Fig. 4. The radioprotective action of Ce-Mil nanocomposite was analyzed after X-ray exposure. Earlier, we have demonstrated radioprotective action of cerium oxide nanoparticles using mouse fibroblasts upon X-ray irradiation [52]. The optimal dose for NCTC L929 cell culture irradiation was selected at $15 \mathrm{~Gy}$. The dose of radiation and cultivation time after irradiation were chosen on the basis of preliminary experiments. Live/Dead and MTT assays were performed 72 hours after X-ray irradiation. It was shown that the $\mathrm{CeO}_{2}$-Mil nanocomposite after X-ray radiation exposure (15 Gy) showed protective action only at the highest concentration $(0.5 \mathrm{mM})$, which ensured the preservation of cell viability by about $25 \%$ compared to the irradiated control. 

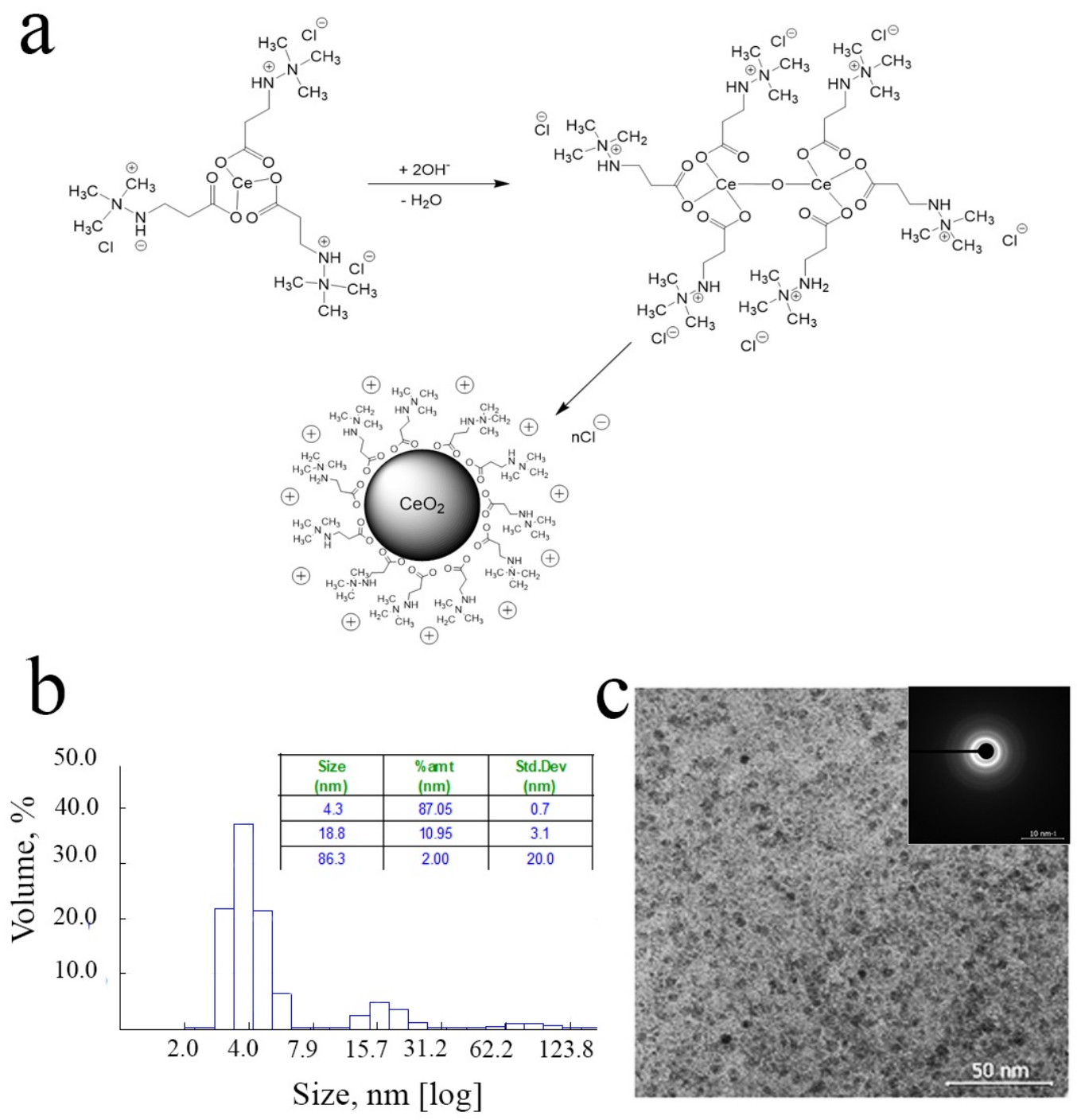

FIG. 1. Synthesis scheme and the structure of the $\mathrm{CeO}_{2}-\mathrm{Mil}$ nanocomposite (a), dynamic light scattering in MQ water (b) and transmission electron microscopy (c)

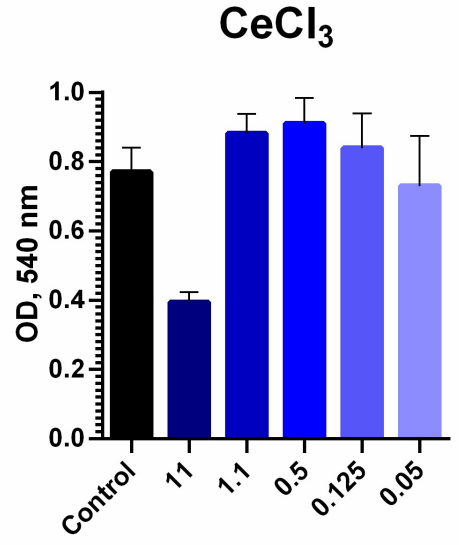

Concentration, $\mathrm{mM}$
Mildronate

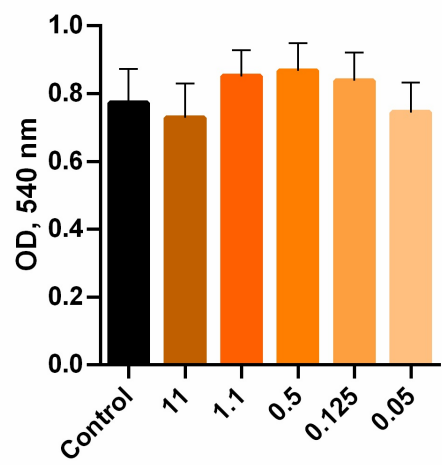

Concentration, $\mathrm{mM}$
Mildronate- $\mathrm{CeO}_{2}$

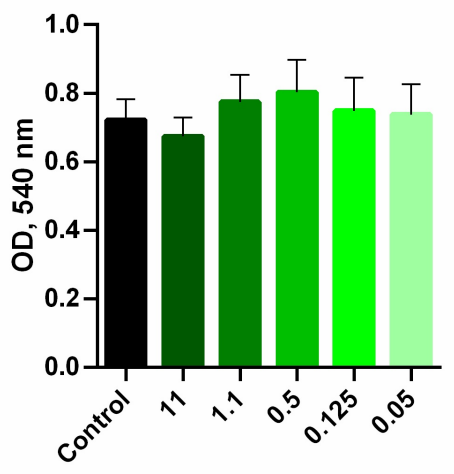

Concentration, $\mathrm{mM}$

FIG. 2. Cytotoxicity analysis by the MTT test of $\mathrm{CeO}_{2}-\mathrm{Mil}$ nanocomposite using NCTC L929 cell line (24 hours after incubation) 

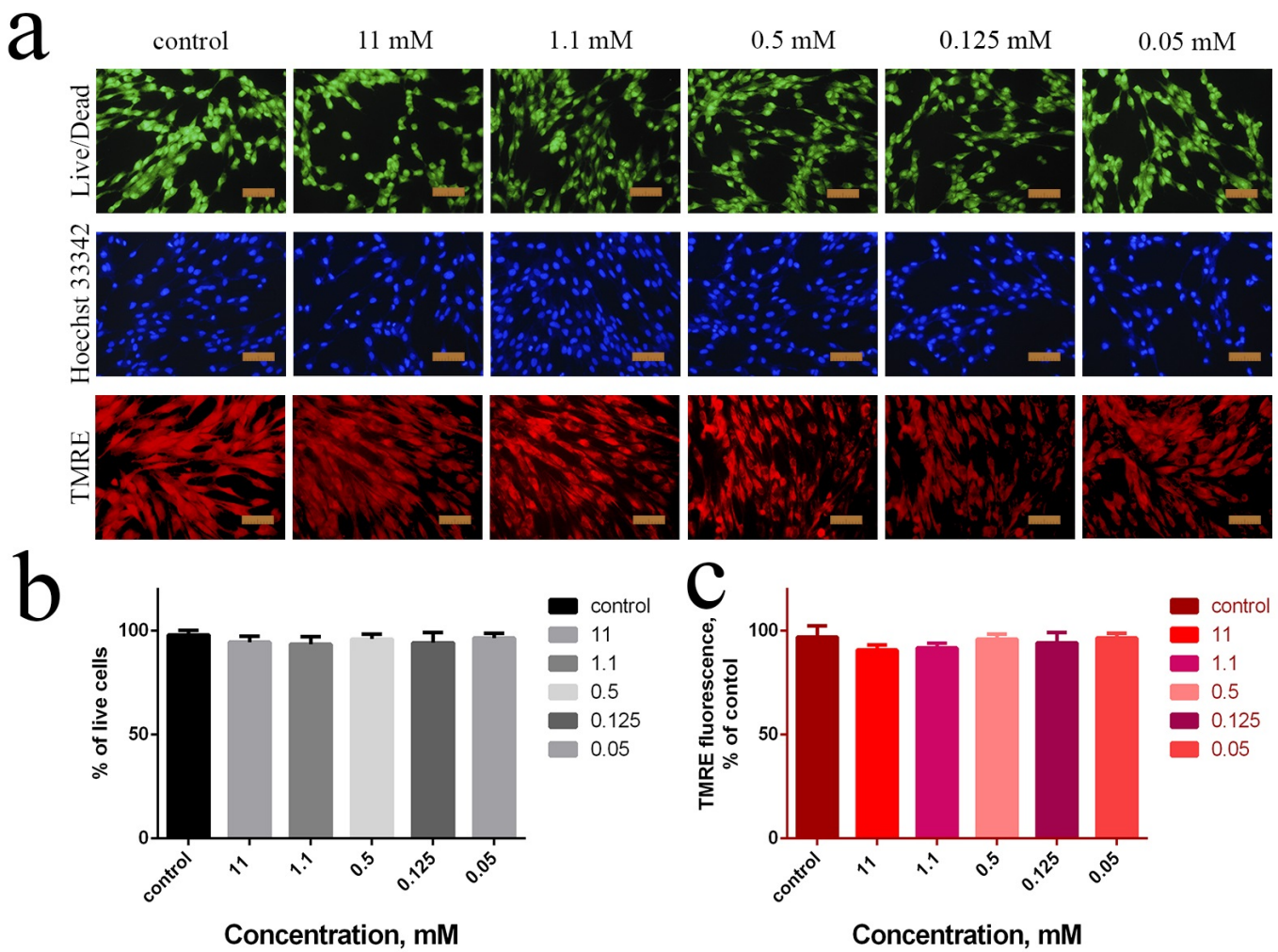

FIG. 3. Microphotographs of NCTC L929 mouse fibroblasts 24 hours after incubation with $\mathrm{CeO}_{2}-\mathrm{Mil}$ nanocomposite (0.05-11 mM) dyed with SYTO9/PI (top line), Hoechst 33342 (middle line) and TMRE (bottom line) (a). Quantitative analysis of live/dead assay (b) and MMP level (c)

\section{$\mathrm{H}_{2} \mathrm{O}_{2}(1 \mathrm{mM})$}

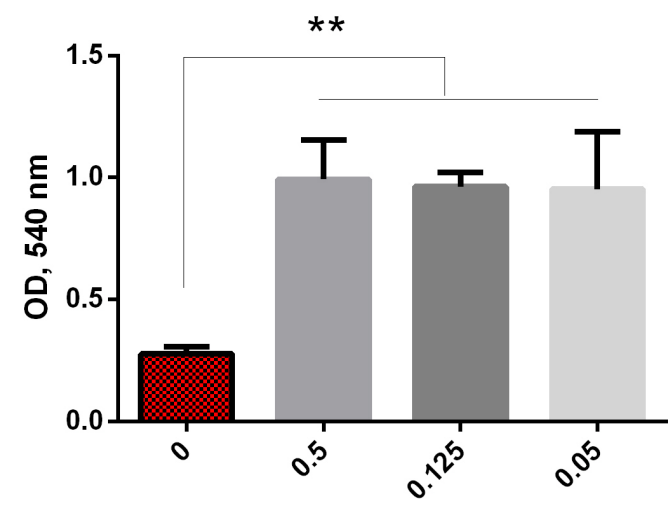

Concentration, mM
X-ray (15 Gy)

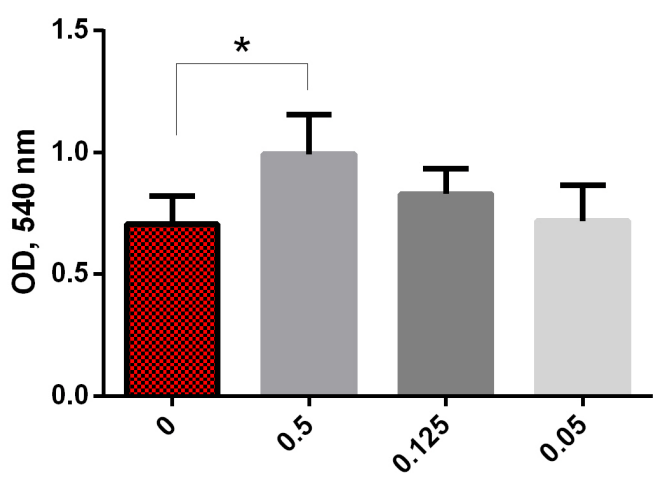

Concentration, $\mathrm{mM}$

FIG. 4. Protective effect of $\mathrm{CeO}_{2}$-Mil nanocomposite (0.05-0.5 mM) on NCTC L929 cell line under oxidative stress conditions induced by $\mathrm{H}_{2} \mathrm{O}_{2}$ treatment (left) and X-ray irradiation (right) as assessed using MTT assay. The cells were pretreated with a $\mathrm{CeO}_{2}-\mathrm{Mil}$ nanocomposite in different concentrations $(0.05-0.5 \mathrm{mM})$ and then exposed to X-ray irradiation $(15 \mathrm{~Gy})$ or treated with hydrogen peroxide $(1 \mathrm{mM}$ for $30 \mathrm{~min})$. Data are presented at mean $\pm \mathrm{SD}$, * $\mathrm{p} \leq 0.05 \%$, ** $\mathrm{p} \leq 0.001 \%$ 
Lower concentrations of $\mathrm{CeO}_{2}$-Mil nanocomposite $(0.125-0.05 \mathrm{mM})$ did not provide a radioprotective effect. Meanwhile, the protective effect of $\mathrm{CeO}_{2}$-Mil nanocomposite upon $\mathrm{H}_{2} \mathrm{O}_{2}$ treatment was observed in all the studied nanocomposite concentrations $(0.05-0.5 \mathrm{mM})$ maintaining a high level of NCTC L929 cell viability close to the control values.

The protective action of the $\mathrm{CeO}_{2}$-Mil nanocomposite under $\mathrm{H}_{2} \mathrm{O}_{2}$ induced oxidative stress can be explained by the pronounced catalase-like activity of the cerium oxide nanoparticles. We assume that the $\mathrm{CeO}_{2}-\mathrm{Mil}_{\text {nanocomposite, after }}$ being introduced into the cell culture, is localized not only in the cytoplasm of the cell, but is also partially adsorbed on the outer surface of cell membranes, which makes it possible to effectively decompose hydrogen peroxide in the selected concentration range $(0.05-0.5 \mathrm{mM})$. At the same time, upon X-ray exposure, oxidative stress and the corresponding damaging factors develop through the water radiolysis inside and outside the cell. When exposed to X-rays, hydroxyl and superoxide radicals are first formed, which can dismutate to hydrogen peroxide. At the same time, it is well known that under acidic conditions, cerium oxide nanoparticles lose their catalase-mimetic activity while maintaining their SODmimetic ability, which leads to the accumulation of $\mathrm{H}_{2} \mathrm{O}_{2}$, being more toxic than superoxides, resulting in the selective radiation-induced cytotoxicity in relation to transformed cells [53]. Cerium oxide nanoparticles possess pronounced antioxidant properties and thus they can inactivate almost all types of ROS and free radicals formed as a result of radiationinduced water radiolysis, including the superoxide anion [54, 55] and hydroxyl radicals [56, 57]. Radiation-induced damage also develops in mitochondria, which is expressed in damage to mitochondrial DNA, uncoupling of the respiratory chain due to the development of oxidative stress, and a drop in the mitochondrial membrane potential [58-60]. Thus, the use of mitochondria-targeted radioprotectors based on cerium oxide can be considered as a promising strategy for protecting healthy surrounding tissue during radiation therapy.

\section{References}

[1] Singh S. Cerium oxide based nanozymes: Redox phenomenon at biointerfaces. Biointerphases, 2016, 11(4), P. $04 \mathrm{~B} 202$.

[2] Saifi M.A., Seal S., Godugu C. Nanoceria, the versatile nanoparticles: Promising biomedical applications. J. Control Release, 2021, 338, P. 164189.

[3] Lord M.S., Berret J.F., Singh S., Vinu A., Karakoti A.S. Redox Active Cerium Oxide Nanoparticles: Current Status and Burning Issues. Small, 2021, 17(51), P. e2102342.

[4] Ivanov V.K., Baranchikov A.E., Ivanova Polezhaeva O.S., Kopitsa G.P., Tretyakov Y.D. Oxygen nonstoichiometry of nanocrystalline ceria. Russian Journal of Inorganic Chemistry, 2010, 55(3), P. 325-327.

[5] Seminko V., Maksimchuk P., Grygorova G., Okrushko E., Avrunin O., Semenets V., Malyukin Y. Mechanism and Dynamics of Fast Redox Cycling in Cerium Oxide Nanoparticles at High Oxidant Concentration. J. Phys. Chem. C, 2021, 125(8), P. 4743-4749.

[6] Malyukin Y., Maksimchuk P., Seminko V., Okrushko E., Spivak N. Limitations of Self-Regenerative Antioxidant Ability of Nanoceria Imposed by Oxygen Diffusion. J. Phys. Chem. C, 2018, 122(28), P. 16406-16411.

[7] Malyukin Y., Klochkov V., Maksimchuk P., Seminko V., Spivak N. Oscillations of Cerium Oxidation State Driven by Oxygen Diffusion in Colloidal Nanoceria $\left(\mathrm{CeO}_{2-x}\right)$. Nanoscale Res Lett, 2017, 12, P. 566.

[8] Shekunova T.O., Lapkina L.A., Shcherbakov A.B., Meshkov I.N., Ivanov V.K., Tsivadze A.Yu., Gorbunova Y.G. Deactivation of singlet oxygen by cerium oxide nanoparticles. Journal of Photochemistry and Photobiology A: Chemistry, 2019, 382, P. 111925.

[9] Xue Y., Luan Q., Yang D., Yao X., Zhou K. Direct evidence for hydroxyl radical scavenging activity of cerium oxide nanoparticles. J. Phys. Chem. $C, 2011,115$, P. 4433-4438.

[10] Plakhova T., Romanchuk A., Butorin S., Konyukhova A., Egorov A., Shiryaev A., Baranchikov A., Dorovatovskii P., Huthwelker T., Gerber E., Bauters S., Sozarukova M., Scheinost A., Ivanov V., Kalmykov S., Kvashnina K. Towards the surface hydroxyl species in $\mathrm{CeO}_{2}$ nanoparticles. Nanoscale, 2019, 11(39), P. 18142-18149.

[11] Das S., Dowding J.M., Klump K.E., McGinnis J.F., Self W., Seal S. Cerium oxide nanoparticles: applications and prospects in nanomedicine. Nanomedicine, 2013, 8, P. 1483-1508.

[12] Bhushan B., Gopinath P. Antioxidant nanozyme: a facile synthesis and evaluation of the reactive oxygen species scavenging potential of nanoceria encapsulated albumin nanoparticles. J Mater Chem B, 2015, 3(24), P. 4843-4852.

[13] Pagliari F., Mandoli C., Forte G., Magnani E., Pagliari S., Nardone G., Licoccia S., Minieri M., Di Nardo P., Traversa E. Cerium Oxide Nanoparticles Protect Cardiac Progenitor Cells from Oxidative Stress. ACS Nano, 2012, 6(5), P. 3767-3775.

[14] Hirst S.M., Karakoti A., Singh S., Self W., Tyler R., Seal S., Reilly C.M. Bio-distribution and in vivo antioxidant effects of cerium oxide nanoparticles in mice. Envirom Toxicology, 2013, 28(2), P. 107-118.

[15] Popov A.L., Zaichkina S.I., Popova N.R., Rozanova O.M., Romanchenko S.P., Ivanova O.S., Smirnov A.A., Mironova E.V., Selezneva I.I., Ivanov V.K. Radioprotective effects of ultra-small citrate-stabilized cerium oxide nanoparticles. RSC Advances, 2016, 6, P. 106141-106149.

[16] Inbaraj S.B., Chen B.H. An overview on recent in vivo biological application of cerium oxide nanoparticles. Asian J Pharm Sci, 2020, 15(5), P. 558-575.

[17] Heckert E.G., Karakoti A.S., Seal S., Self W.T. The role of cerium redox state in the SOD mimetic activity of nanoceria. Biomaterials, 2008, 29(18), P. 2705-9.

[18] Zhao H., Zhang R., Yan X., Fan K. Superoxide dismutase nanozymes: an emerging star for anti-oxidation. J. Mater. Chem. B, 2021, 9, P. 69396957.

[19] Heckert E.G., Karakoti A.S., Seal S., Self W.T. The role of cerium redox state in the SOD mimetic activity of nanoceria. Biomater, 2008, 29, P. 2705-2709.

[20] Baldim V., Bedioui F., Mignet N., Margaill I., Berret J.-F. The enzyme-like catalytic activity of cerium oxide nanoparticles and its dependency on $\mathrm{Ce}^{3+}$ surface area concentration. Nanoscale, 2018, 10, P. 6971-6980.

[21] Shcherbakov A., Zholobak N., Spivak N., Ivanov V. Advances and prospects of using nanocrystalline ceria in cancer theranostics. Russian Journal of Inorganic Chemistry, 2014, 59(13), P. 1556-1575.

[22] Zeng L., Cheng H., Dai Y., Su Z., Wang C., Lei L., Lin D., Li X., Chen H., Fan K., Shi S. In Vivo Regenerable Cerium Oxide Nanozyme-Loaded $\mathrm{pH} / \mathrm{H}_{(2)} \mathrm{O}_{(2)}$-Responsive Nanovesicle for Tumor-Targeted Photothermal and Photodynamic Therapies. ACS Appl Mater Interfaces, 2021, 13(1), P. 233-244. 
[23] Nourmohammadi E., Khoshdel-Sarkarizi H., Nedaeinia R., Darroudi M., Kazemi Oskuee R. Cerium oxide nanoparticles: A promising tool for the treatment of fibrosarcoma in-vivo. Mater Sci Eng C Mater Biol Appl, 2020, 109, P. 110533.

[24] Qi M., Li W., Zheng X., Li X., Sun Y., Wang Y., Li C., Wang L. Cerium and Its Oxidant-Based Nanomaterials for Antibacterial Applications: A State-of-the-Art Review. Front. Mater, 2020, 7.

[25] Zamani K., Allah-Bakhshi N., Akhavan F., Yousefi M., Golmoradi R., Ramezani M., Bach H., Razavi S., Irajian G.R., Gerami M., Pakdin-Parizi A., Tafrihi M., Ramezani F. Antibacterial effect of cerium oxide nanoparticle against Pseudomonas aeruginosa. BMC Biotechnol, 2021, 21(1), P. 68.

[26] Pop O.L., Mesaros A., Vodnar D.C., Suharoschi R., Tăbăran F., Mageruşan L., Tódor I.S., Diaconeasa Z., Balint A., Ciontea L., Socaciu C. Cerium Oxide Nanoparticles and Their Efficient Antibacterial Application In Vitro against Gram-Positive and Gram-Negative Pathogens. Nanomaterials (Basel), 2020, 10(8), P. 1614.

[27] Shydlovska O., Kharchenko E., Osenniy I., Spivak M., Shcherbakov A., Zholobak N. Nanoparticles of cerium dioxide - an effective antiviral agent and adjuvant of biologically active molecules. ScienceRise Biological Science, 2018, 1(10).

[28] Neal C.J., Fox C.R., Sakthivel T.S., Kumar U., Fu Y., Drake C., Parks G.D. Seal S. Metal-Mediated Nanoscale Cerium Oxide Inactivates Human Coronavirus and Rhinovirus by Surface Disruption. ACS Nano, 2021, 15(9), P. 14544-14556.

[29] Mohamed H.E.A, Afridi S., Khalil A.T, Ali M.., Zohra T, Akhtar R., Ikram A., Shinwari Z.K., Maaza M. Promising antiviral, antimicrobial and therapeutic properties of green nanoceria. Nanomedicine (Lond), 2020, 15(5), P. 467-488.

[30] Shcherbakov A.B., Zholobak N.M., Ivanov V.K. Biological, biomedical and pharmaceutical applications of cerium oxide. Cerium Oxide (CeO?): Synthesis, Properties and Applications, 2020, P. 279-358.

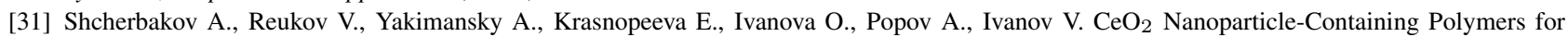
Biomedical Applications: A Review. Polymers, 2021, 13(6), P. 924.

[32] Yang B., Chen Y., Shi J. Reactive Oxygen Species (ROS)-Based Nanomedicine. Chem Rev, 2019, 119(8), P. 4881-4985.

[33] Krysanov E., Demidova T., Ivanova O., Ordzhonikidze K., Shcherbakov A., Ivanov V. Synergetic action of ceria nanoparticles and doxorubicin on the early development of two fish species, Danio rerio and Puntius tetrazona. Nanosystems: Physics, Chemistry, Mathematics, 2019, 10(3), P. 289-302.

[34] Xu C., Lin Y., Wang J., Wu L., Wei W., Ren J., Qu X. Nanoceria-triggered synergetic drug release based on CeO 2 -capped mesoporous silica host-guest interactions and switchable enzymatic activity and cellular effects of $\mathrm{CeO}_{2}$ Adv Healthc Mater., 2013, 2(12), P. 1591-9.

[35] Liu X., Liu J., Chen S., Xie Y., Fan Q., Zhou J., Bao J., Wei T., Dai Z. Dual-path modulation of hydrogen peroxide to ameliorate hypoxia for enhancing photodynamic/starvation synergistic therapy. J Mater Chem B, 2020, 8(43), P. 9933-9942.

[36] Barkam S., Das S., Saraf S., McCormack R., Richardson D., Atencio L., Moosavifazel V., Seal S. The change in antioxidant properties of dextrancoated redox active nanoparticles due to synergetic photoreduction-oxidation. Chemistry, 2015, 21(36), P. $12646-56$.

[37] Zholobak N. M., Shcherbakov A. B., Bogorad-Kobelska A. S., Ivanova O. S., Baranchikov A. Ye., Spivak N. Ya., Ivanov V. K. Panthenol-stabilized cerium dioxide nanoparticles for cosmeceutic formulations against ROS-induced and UV-induced damage. J Photochem Photobiol B, 2014, 130, P. 102-108.

[38] Zholobak N.M., Shcherbakov A.B., Ivanova O.S., Reukov V., Baranchikov A.E., Ivanov V.K. Nanoceria-curcumin conjugate: synthesis and selective cytotoxicity against cancer cells under oxidative stress conditions. J. Photochem. Photobiol. B, 2020, 209, P. 111921.

[39] Shydlovska O., Kharchenko E., Zholobak N., Shcherbakov A., Marynin A., Ivanova O., Baranchikov A., Ivanov V. Cerium oxide nanoparticles increase the cytotoxicity of TNF-alpha in vitro. Nanosystems: Phys. Chem. Math., 2018, 9(4), P. 537-543.

[40] Pupure J., Fernandes M. A. S., Santos M. S., Moreno A. J. M., Kalvinsh I., Klusa V., Oliveira C. R. Mitochondria as the target for mildronate's protective effects in azidothymidine (AZT)-induced toxicity of isolated rat liver mitochondria. Cell Biochem Funct, 2008,26, P. 620-631.

[41] Pupure J., Isajevs S., Skapare E., Rumaks J., Svirskis S., Svirina D., Kalvinsh I., Klusa V. Neuroprotective properties of mildronate, a mitochondriatargeted small molecule. Neurosci Lett, 2010, 470(2), P. 100-105.

[42] Wang C., Youle R.J. The Role of Mitochondria in Apoptosis. Annu Rev Genet, 2009, 43, P. 95-118.

[43] Lin M.T., Beal M.F. Mitochondrial dysfunction and oxidative stress in neurodegenerative diseases. Nature, 2006, 443(7113), P. 787-795.

[44] Luo Y., Ma J., Lu W. The Significance of Mitochondrial Dysfunction in Cancer. Int J Mol Sci, 2020, 21(16), P. 5598.

[45] Asati A., Santra S., Kaittanis C., Perez J.M. Surface-Charge-Dependent Cell Localization and Cytotoxicity of Cerium Oxide Nanoparticles. ACS Nano, 2010, 4(9), P. 5321-5331.

[46] Ma Y., Li P., Zhao L., Liu J., Yu J., Huang Y., Zhu Y., Li Z., Zhao R., Hua S., Zhu Y., Zhang Z. Size-Dependent Cytotoxicity and Reactive Oxygen Species of Cerium Oxide Nanoparticles in Human Retinal Pigment Epithelia Cells. Int J Nanomedicine, 2021 , 16, P. 5333-5341.

[47] García-Salvador A., Katsumiti A., Rojas E., Aristimuño C., Betanzos M., Martínez-Moro M., Moya S.E., Goñi-de-Cerio F. A Complete In Vitro Toxicological Assessment of the Biological Effects of Cerium Oxide Nanoparticles: From Acute Toxicity to Multi-Dose Subchronic Cytotoxicity Study. Nanomaterials (Basel), 2021, 11(6), P. 1577.

[48] Popov A.L., Popova N.R., Selezneva I.I., Akkizov A.Y., Ivanov V.K. Cerium oxide nanoparticles stimulate proliferation of primary mouse embryonic fibroblasts in vitro. Materials Science and Engineering C, 2016, 68, P. 406-413.

[49] Popov A., Abakumov M., Savintseva I., Ermakov A., Popova N., Ivanova O., Kolmanovich D., Baranchikov A., Ivanov V. Biocompatible dextrancoated gadolinium-doped cerium oxide nanoparticles as MRI contrast agents with high T1 relaxivity and selective cytotoxicity to cancer cells. $J$. Mater. Chem. B, 2021, 9, P. 6586-6599.

[50] Xiong S., Mu T., Wang G., Jiang X. Mitochondria-mediated apoptosis in mammals. Protein Cell, 2014,5 P. 737-749.

[51] Jana S.K., Banerjee P., Das S., Seal S. Chaudhury K. Redox-active nanoceria depolarize mitochondrial membrane of human colon cancer cells. J. Nanopart. Res., 2014, 16, P. 2441.

[52] Xu P.T., Maidment B.W., Antonic V., Jackson I.L., Das S., Zodda A., Zhang X., Seal S., Vujaskovic Z. Cerium Oxide Nanoparticles: A Potential Medical Countermeasure to Mitigate Radiation-Induced Lung Injury in CBA/J Mice. Radiat Res, 2016, 185(5), P. 516-526.

[53] Perez J.M., Asati A., Nath S., Kaittanis C. Synthesis of Biocompatible Dextran-Coated Nanoceria with pH-Dependent Antioxidant Properties. Small, 2008, 4(5), P. 552-556.

[54] Akhtar M.J., Ahamed M., Alhadlaq H. Anti-Inflammatory $\mathrm{CeO}_{2}$ Nanoparticles Prevented Cytotoxicity Due to Exogenous Nitric Oxide Donors via Induction Rather Than Inhibition of Superoxide/Nitric Oxide in HUVE Cells. Molecules, 2021, 26(17), P. 5416.

[55] Akhtar M.J., Ahamed M., Alhadlaq H. Anti-Inflammatory $\mathrm{CeO}_{2}$ Nanoparticles Prevented Cytotoxicity Due to Exogenous Nitric Oxide Donors via Induction Rather Than Inhibition of Superoxide/Nitric Oxide in HUVE Cells. Molecules, 2021, 26(17), P. 5416.

[56] Zou S., Zhu X., Zhang L., Guo F., Zhang M., Tan Y., Gong A., Fang Z., Ju H., Wu C., Du F. Biomineralization-Inspired Synthesis of Cerium-Doped Carbonaceous Nanoparticles for Highly Hydroxyl Radical Scavenging Activity. Nanoscale Res Lett, 2018, 13(1), P. 76.

[57] Zhai J.H., Wu Y., Wang X.Y., Cao Y., Xu K., Xu L., Guo Y. Antioxidation of Cerium Oxide Nanoparticles to Several Series of Oxidative Damage Related to Type II Diabetes Mellitus In Vitro. Med Sci Monit., 2016, 22, P. 3792-3797. 
[58] Leach J.K., Van Tuyle G., Lin P. S., Schmidt-Ullrich R., Mikkelsen R.B. Ionizing radiation-induced, mitochondria-dependent generation of reactive oxygen/nitrogen. Cancer Res, 2001, 61(10), P. 3894-3901.

[59] Averbeck D., Rodriguez-Lafrasse C. Role of Mitochondria in Radiation Responses: Epigenetic, Metabolic, and Signaling Impacts. Int J Mol Sci.,2021, 22(20), P. 11047.

[60] Murray V., Hardie M.E., Gautam S.D. Comparison of Different Methods to Determine the DNA Sequence Preference of Ionising RadiationInduced DNA Damage. Genes (Basel), 2019, 11(1), P. 8.

Submitted 11 January 2022; accepted 31 January 2022

Information about the authors:

A. L. Popov - Institute of Theoretical and Experimental Biophysics of the Russian Academy of Sciences, Institutskaya str., 3, Pushchino, 142290, Russia; antonpopovleonid@gmail.com

D. D. Kolmanovich - Institute of Theoretical and Experimental Biophysics of the Russian Academy of Sciences, Institutskaya str., 3, Pushchino, 142290, Russia; kdd100996@mail.ru

N. R. Popova - Institute of Theoretical and Experimental Biophysics of the Russian Academy of Sciences, Institutskaya str., 3, Pushchino, 142290, Russia; nellipopovaran@gmail.com

S. S. Sorokina - Institute of Theoretical and Experimental Biophysics of the Russian Academy of Sciences, Institutskaya str., 3, Pushchino, 142290, Russia; sorokinasvetlana.iteb@gmail.com

O. S. Ivanova - Kurnakov Institute of General and Inorganic Chemistry of the Russian Academy of Sciences, Leninskiy prosp., 31, Moscow, 119991, Russia; runetta05@mail.ru

N. N. Chukavin - Institute of Theoretical and Experimental Biophysics of the Russian Academy of Sciences, Institutskaya str., 3, Pushchino, 142290, Russia; Moscow Region State University, 141014 Moscow, Russia; chukavinnik@gmail.com

A. B. Shcherbakov - Zabolotny Institute of Microbiology and Virology, National Academy of Sciences of Ukraine, Kyiv D0368, Ukraine; ceroform@gmail.com

T. O. Kozlova - Kurnakov Institute of General and Inorganic Chemistry of the Russian Academy of Sciences, Leninskiy prosp., 31, Moscow, 119991, Russia; tasiok@mail.ru

S. A. Kalashnikova - 40th City clinical hospital, Volgogradskaya st., 189, Yekaterinburg, 620102, Russia; kalashnikova.sana@mail.ru

V. K. Ivanov - Kurnakov Institute of General and Inorganic Chemistry of the Russian Academy of Sciences, Leninskiy prosp., 31, Moscow, 119991, Russia; van@igic.ras.ru

Conflict of interest: the authors declare no conflict of interest. 